\title{
Challenges of Tomorrow-Fire Hazards of Systems Using Renewable Sources of Energy
}

\author{
Miloš Banjac ${ }^{1}$ and Barbara Vidaković ${ }^{2}$ \\ 1. Faculty of Mechanical Engineering, University of Belgrade, Belgrade 11000, Serbia \\ 2. Tehnikum Taurunum, The College of Engineering Science, Belgrade 11000, Serbia
}

Received: November 27, 2013 / Accepted: January 02, 2014 / Published: June 30, 2014.

\begin{abstract}
Dramatic climate change, caused by over consumption of coal, oil and other traditional energy sources, as well as exhaustion of their reserves, imposed technological need to look for their substitution with new, renewable energy sources. The exploitation of these new forms of energy, solar, wind, earth and bio-fuels, initiated the development and application of new technologies, so far unused in practice. Rapid development and wide application of installations for use of renewable energy in many households and companies opened a whole new risk and danger in the fire protection field. With the purpose of introducing this problem to engineers in the area of fire protection, health and safety at work, this paper systematically presents various types of facilities for exploitation of renewable energy sources as well as potential dangers, risks and issues related to their safe operation.
\end{abstract}

Key word: Fire hazard, renewable energy sources, risk assessment, protection.

\section{Introduction}

Generally speaking, we may say that the technological development of civilization came to an end of an era when fossil fuels, conventional or non-renewable sources of energy are the basis for planning future development. Furthermore, we are living in times when energy technologies are constantly and rapidly changing. Obviously, consumers and companies are turning to the use of renewable energy sources and technologies that provide its use. Sustainable development and use of renewable energy sources are becoming the world's main topic, and governments of many countries are increasingly trying, through special programs and various measures, to stimulate their use. Application of new technology brings with itself new risk of fire hazard. In order to ensure a safe use of these technologies first, we are obliged to notice the places of

Corresponding author: Miloš Banjac, associate professor, research fields: renewable energy and energy policy. E-mail: mbanjac@mas.bg.ac.rs. potential risks, then find ways to overcome them, and finally develop procedures that will reduce them to an acceptable level.

Although, it seems at first glance that these changes are far away from Serbia, it is important to point out that the Republic of Serbia, after more than three years of long negotiations, on the 10th Council of Ministers meeting held on 18th of the Energy Community October 2012 in Budva, assumed the obligation of the implementation of Directive 2009/28/EC-the so-called Directive on Renewable Energy. Thanks to this act Serbia joined other member states of the European Union in an effort to preserve the environment by increasing the use of RES (renewable energy sources). Expressed in percentages, Serbia is committed to increase the share of RES from $21.2 \%, 2009$ to $27 \%$, 2020 and increase the consumption of biofuels in the transport sector from 0 to $10 \%$ in the same period. In other words, in units of energy, until 2020 Serbia needs to increase its energy capacity so as to be capable to produce new 0.621 Mtoe using renewable energy 
sources.

Thus, a new era should begin in Serbia based on serious exploitation of RES technologies and consequently there is a deep need to consider new areas of risk and fire hazard. In response to this, for Serbia very urgent issue, this work provides an overview of the main RES technologies, and potential fire hazards that may occur during their use, as well as the procedures and problems of intervention of fire-fighters in the case of fire.

\section{What are RES?}

RES, sometimes denoted as permanent energy sources, are used to generate electricity or thermal energy, or any other useful work, and those reserves that are constantly present in the nature, or are able to recycle or regenerate faster than the speed at which they exhaust themselves. Some of RES are claimed to have so many reserves that they can be exploited for millions of years. In the case of non-renewable resources, reserves are estimated at tens or hundreds of years, and their creation took tens of millions of years.

According to the definition of the International Energy Agency "renewable energy is energy that is derived from natural processes that are replenished at a higher rate than they are consumed" [1]. In its various forms, it derives directly from the Sun, or from heat generated deep within the Earth.

Included in the definition are electricity and heat generated from solar, wind, ocean, hydropower, biomass, geothermal resources, biofuels and hydrogen derived from renewable resources. EU (European Union) and domestic legislation are somewhat more precise in defining, and thus the DIRECTIVE 2009/28/EC [2] and Serbian Law on Energy [3] define that "energy from renewable sources means energy from renewable non-fossil sources, namely wind, solar, aero thermal, geothermal, hydrothermal and ocean energy, hydropower, biomass, landfill gas, sewage treatment plant gas and biogases". At the same time, the Regulation on conditions for acquiring the status of privileged producer of electricity, expands and supplements this definition, with the notion that "renewable energy sources are energy sources that are found in nature and reproduced in whole or in part, in particular energy of water flows, wind energy, solar energy, biomass, animal origin biomass, geothermal energy, biofuels, biogas, synthetic gas, landfill gas, gas from plants for the treatment of municipal water and wastewater from food processing and wood processing industries that do not contain hazardous materials" [4].

\subsection{Systems that Use Solar Energy}

Systems which use solar energy are of significant interest from the perspective of fire protection. According to the purpose, work principle and the way of using of sunlight, there are two basic types of devices that use solar energy and convert it to heating or electricity energy.

A STC (solar thermal collector) is a solar collector designed to collect heat by absorbing sunlight. A collector is a device for converting the energy in sunlight, or solar radiation, into a more usable or storable form. This energy is in the form of electromagnetic radiation from the infrared (long) to the ultraviolet (short) wavelengths. The quantity of solar energy striking the Earth's surface averages about 1,000 watts per square meter under clear skies, depending upon weather conditions, location, and orientation of the surface.

Another type of seemingly similar devices, but by purpose completely different, is solar cells. A solar cell, also called a PV (photovoltaic) cell is an electrical device that converts the energy of light directly into electricity by the photovoltaic effect. It is a form of PV cell (in that its electrical characteristics, e.g., current, voltage or resistance-vary when light is incident upon it) which, when exposed to light, can generate and support an electric current without being attached to any external voltage source.

Since both of these systems operate at higher temperatures and there is no possibility of shutting them 


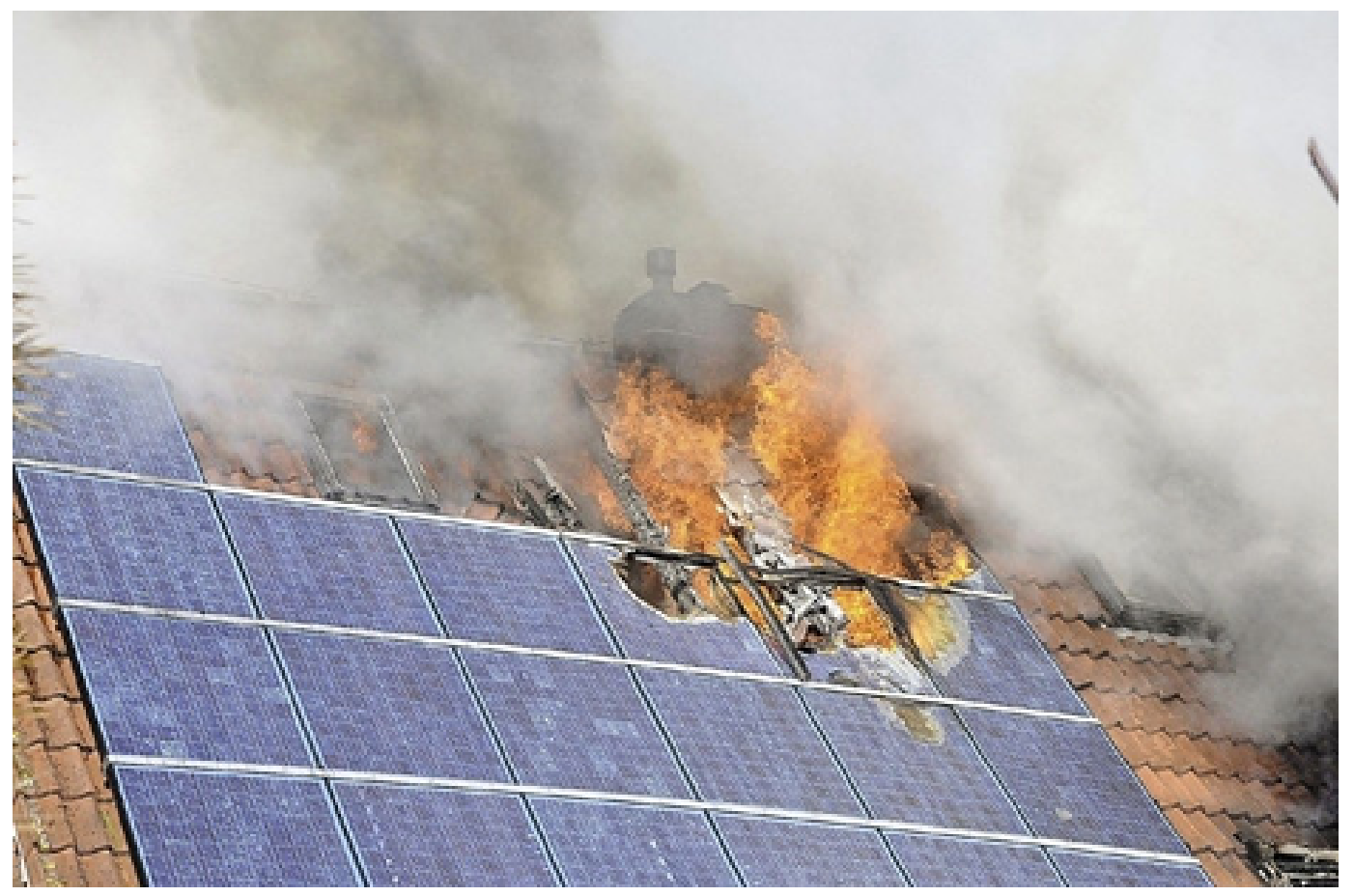

Fig. 1 A fire on the roof with PV panels-Burstadt, Germany, 2009 [5].

off, there is a potential danger for their overheating, and therefore, a potential risk of fire. The fire risk increases in the case of setting STC or PV panels on a wooden roof and/or their incorrect design (Fig. 1).

However, they represent a more significant fire risk in the sense of obstructing fire extinguishing in the case of already incurred fire. If they are placed on the roof, their weight could further weaken the earing capacity of the roof. Because of its fragile, brittle and slippery structures, standing and crossing them is difficult and risky, and represent an obstacle and a nuisance in intervention. If the PV or TSC plates are incorrectly installed, that might restrict or disable the use of roof windows as an alternative evacuation route.

In case of TSC, there is a real risk of leakage of hot working fluids which they contain. In the case of PV systems, the low voltage current is present in installation and after converter the high voltage as well. Since the system cannot be turned off in the section of low voltage, there is a risk of electric shock for firemen. That could also cause a problem in the procedure of breaking the panels in order to remove smoke. Besides, the high voltage detectors will not be useful, because they not able to detect low voltage current.

For all types of solar systems, consideration needs to be given to maintaining full access by fire fighters on rooftops and on other sections of a building where fire-fighters operate during an emergency situation. Advancing solar technologies now include devices beyond traditional panels, such as photovoltaic fabrics and films that can be installed in any orientation (e.g., on a vertical surface) and that can introduce questions concerning flame spread. New products also include building components such as photovoltaic roofing shingles and tiles, which present hazards to fire-fighters and others that are not readily obvious.

\subsection{Wind Power}

In ancient times, man found a way to use wind energy (eolic energy). In the past, wind energy was used by conversion into a useful form of energy —windmills for mechanical power, windpumps for water pumping or drainage, or sails to propel ships.

Although even today in some places wind energy is used for this purposes, in recent times it has been used primarily used to make electrical power. This is why 
the plants that perform this transformation of energy are called wind power plants (also known as windmills, wind generators, wind turbines). As wind power grows exponentially with increasing distance from the surface of the earth, the height and strength of wind turbines are steadily increasing. In eighties of last century, the usual maximum capacity of these plants was about 30 $\mathrm{kW}$ and a maximum height of wind turbines towers about $30 \mathrm{~m}$. Today, although there are those whose capacity is up $6 \mathrm{MW}$ and a height $130 \mathrm{~m}$, the usual capacity of a wind turbines is about $1 \mathrm{MW}$ and height of the tower of about $50 \mathrm{~m}$.

The wind power plants consiste of power generators mounted atop a tall bearing pillar, in which electricity is generated based on rotation of the large wind propeller-driven. Thus, a wind turbine itself has the same type of fire risk as any other generator of electricity. The only difference is that the wind-generator is located on a very high position and thus less accessible location (Fig. 2). Because of inaccessibility, extinguishing fires in the wind turbines are possible only if they already have built-in automatic detection systems and stationary fire extinguishing systems. The importance of installing these systems is even greater, because the wind power plants are usually far from urban areas (due tonoise and the necessity to put them in the areas exposed to winds), so that they are out of reach of emergency services.

It is important to emphasize that because of their height and metal construction, wind turbines towers and the rotor blades are often exposed to lightning strikes, so it is necessary to protect them against lightning strikes among other reason also because of the fire protection.

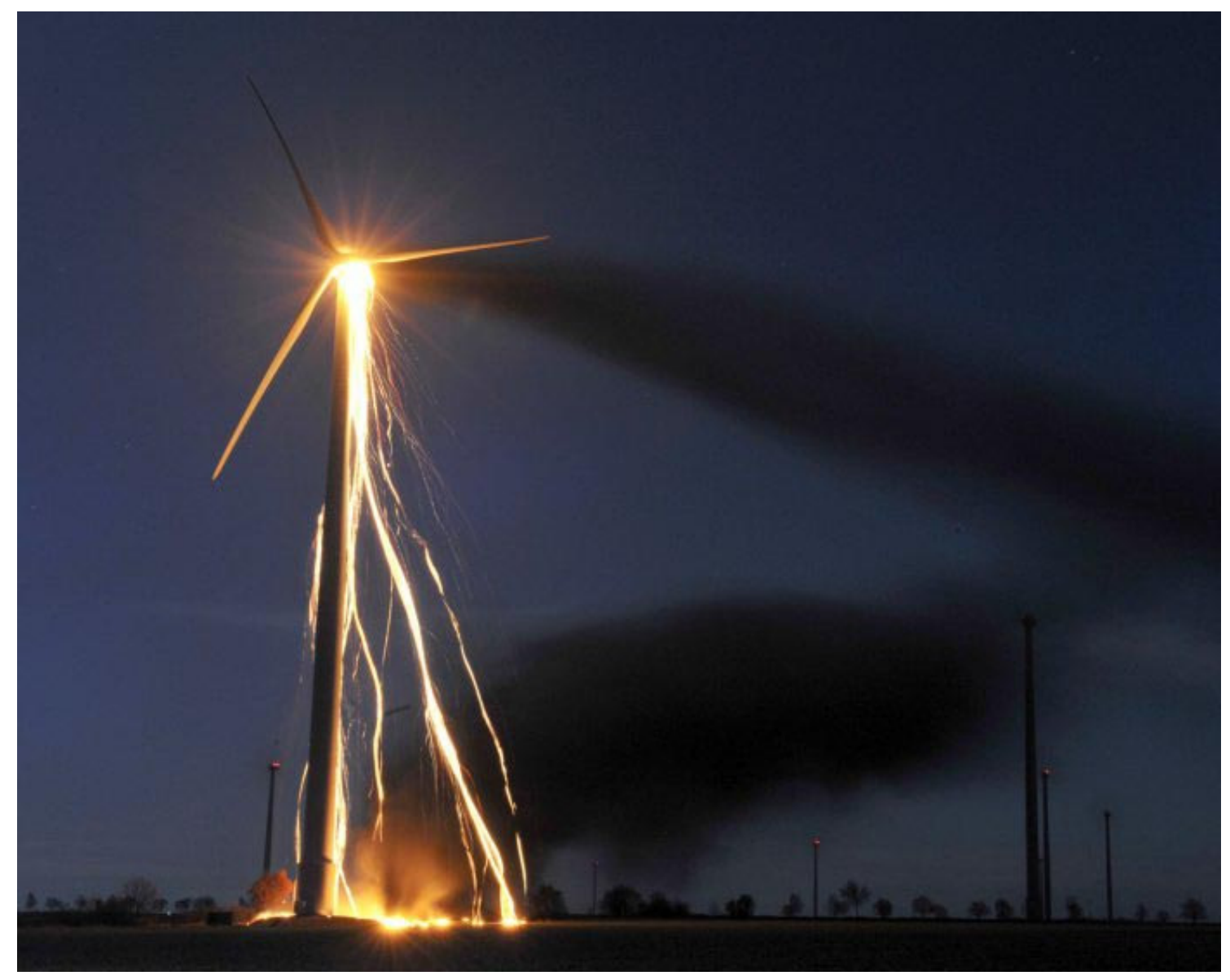

Fig. 2 Wind turbine fire near Uelzen, lower Saxony, Germany, December 2nd, 2009 [6]. 
However, in the rare cases where the wind turbines pillars (low power) are placed on or near to a building, even during the design phase, special attention should be paid to bearing capacity of this structure.

\subsection{Biomass}

Biomass is the biodegradable fraction of products, waste and residues from biological origin from agriculture (including vegetal and animal substances), forestry and related industries including fisheries and aquaculture, as well as the biodegradable fraction of industrial and municipal waste [1]. Biomass can be in solid, liquid (e.g., biodiesel, bioethanol and biomethanol) and gaseous state (e.g., biogas, gas generated by decomposition of biomass and landfill gas).

According to its origin the biomass is usually divided into wood origin biomass, nonwood origin biomass and biomass from animal waste, within which it can be distinguished:

- woody biomass (wood, wood waste, residues from forestry and wood processing);

- wood biomass in the form of semi-products for combustion (briquettes, pellets and chips);

- silvicultural wood biomass (fast-growing trees); nonwood silvicultural biomass (all kinds of cereals, sugar cane, sugar beet, oilseed rape, a fast growing algae and grasses);

- residues and waste from agriculture (straw, corn stalks, cobs, stems, seeds, shells, etc.);

- animal waste and residues.

\subsection{Liquid Biofuels}

Production of liquid biofuels is overall a special area of RES, both according to the applied technology and later use of the product. The most famous representatives of liquid biofuels are bio-ethanol (bio-alcohol) and bio-diesel.

Bio-ethanol is usually produced by processing of sugar cane, sugar beets, corn or wood in a relatively complex technological-chemical process that includes preparation of raw materials, fermentation and finally distillation of ethanol.

Biodiesel is the commercial name under which the methyl ester, without additional mineral diesel fuel, is found on the market and sales end users. It is already a standardized liquid no mineral fuel. Biodiesel is non-toxic and biodegradable fuel and can completely be used as replacement for conventional mineral diesel fuel. It can be produced from vegetable oils (rapeseed, soybean, sunflower, palm and castor oil), recycled waste cooking oil or by esterification process of animal fat, where glycerine is obtained as a by-product.

Fire risks in the use of bio-diesel and bio-alcohol differ slightly in comparison to the hazards associated with the use of conventional mineral petrol and diesel. As to the fact that bio-ethanol (alcohol) has a lower flash point temperature than mineral petrol, use and handling of bio-ethanol is even less risky in terms of the explosion and the fire hazard. On the other hand, the fire risk in handling and usage of the biodiesel in equated with mineral diesel. Plants and industry for producing liquid biofuels should comply with the regulations and defined procedures for handling hazardous substances and explosive atmospheres, and regulations for fire protection. At the same time, definition and classification of hazardous areas should be one of the main elements of the protection of a risk analysis.

\subsection{Biomass for Use with Boilers}

Although in Serbia, the most common use of biomass is in cut wood form, in such a form it is not suitable for industrial use. Besides, the mentioned way of using wood is the most primitive and in terms of energy efficiency the worst way for its use. Therefore, it is desirable to use as fuel primarily waste wood, residues from forestry and the wood processing industry, and in the form of wood chips or semi-products such as briquettes and pellets.

Fire risks in the use of all types of biomass in the solid state, and biogas as fuel in boilers, as well as in the use of conventional fuels, are related to potential fire hazards in combustion process and the risks 


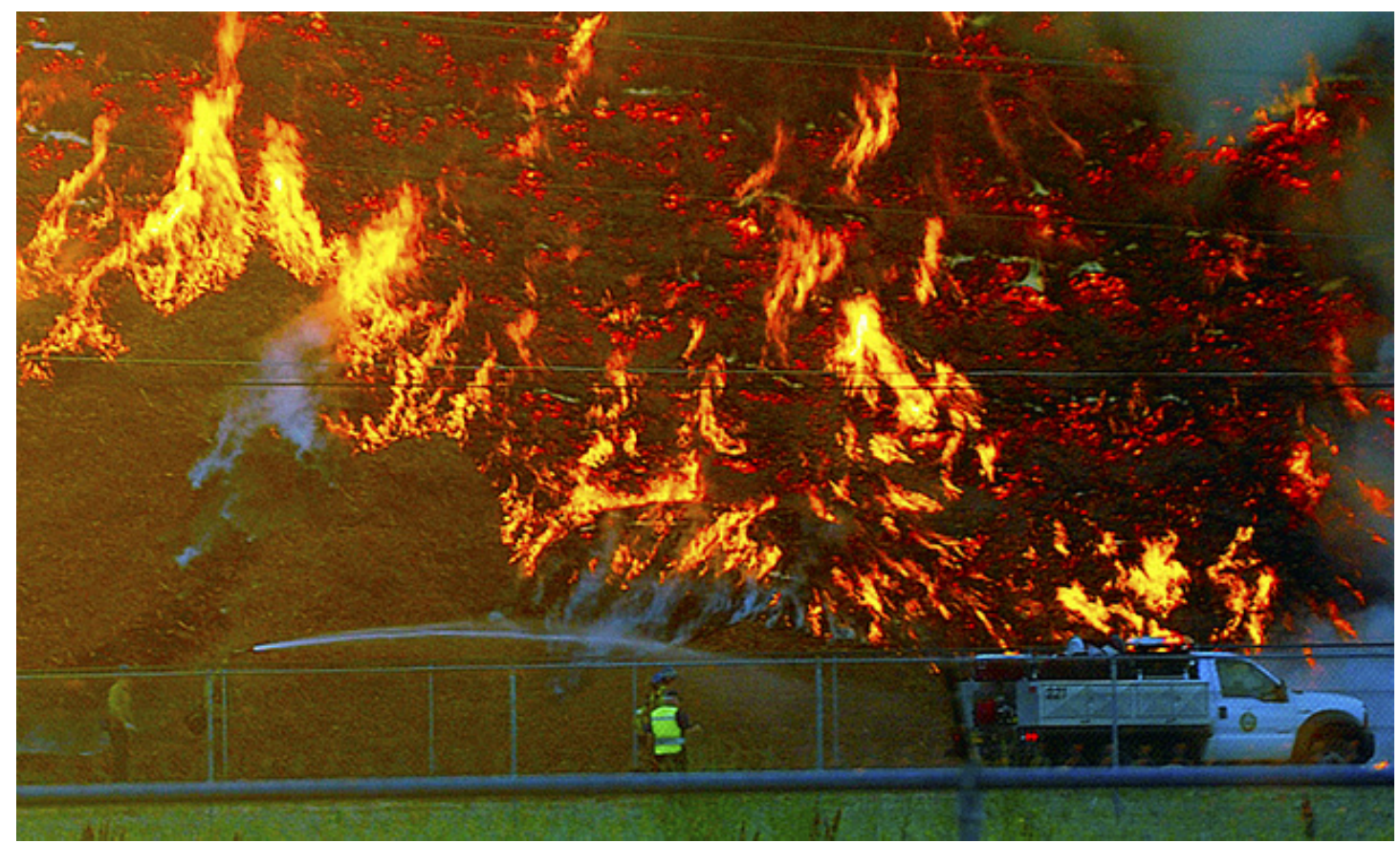

Fig. 3 Quenching of sawdust fire-White City, Oregon, USA, July, September 2009 [7].

associated with the process combustion, as well as hazards of present materials and equipment. In the case of solid biofuels, there is a potential risk of self-heating and self-ignition of the landfill, then a risk of dust explosion, which is always present, especially in the transport and transshipment of this type of biofuel (Fig. 3). An especially large fire hazard is present in cases where is necessary to undergo fuel to drying process for preparing for combustion In those cases, a coordination and control of the moisture content, temperature and drying time are necessary.

All these said risks are associated with a potential risk to human life, property and business. Therefore, it is necessary that all these areas should be covered by detail relevant regulations such as fire protection, safety and health at work.

\subsection{Biogas}

Biogas is the most famous representative of the bio origin energy in the gaseous state. It is generated during the process of anaerobic digestion of biomass, specifically by:

- residues from agriculture (liquid manure, manure from livestock and poultry farms, and silage);
- biomass residues generated in primary processing of agricultural products (which do not contain hazardous substances);

- other biomass, which does not contain hazardous materials, residues and parts of animals.

Installations for production of the biogas have extremely large fire hazards and risks of explosion. The composition of biogas depends on the type and characteristics of waste of its origin, the anaerobic process and process time. Usually, a biogas consists mainly of methane and carbon dioxide (and other trace components, e.g., Sulfur-hydrogen) [8], of which 50\% to $75 \%$ of the gas is methane. It is important to point than methane in certain concentrations in air easily form dangerous explosive mixture and that represents a serious risk. Therefore, it is necessary to take care of limits of explosivity of methane in the air and permanently measure its concentrations in the air. LEL (lower explosive limit) of methane in the air is 4.4 vol.\% and the UEL (upper explosive limit) is 16.5 vol.\% [9]. Within these limits it may cause an ignition or explosion under normal ambient conditions.

Since the explosion can cause loss of life, serious injuries, and significant property damage, biogas 
production is regulated by two EU Directive known as ATEX Directive (Directive 99/92/EC-'ATEX 137' and Directive 94/9/EC-'ATEX 95') [10, 11].

\subsection{Geothermal Energy}

The word geothermal a compound term coined from two Greek words-geo (earth) and thermo (heat) and it means heat of the earth; therefore the heat of the Earth also is called geothermal energy. The heat inside the Earth is the result of slow radioactive decay of elements, chemical reactions, and motion of tectonic plates. The geothermal energy potential is enormous; there is 50,000 times more than all the energy that can be obtained from oil and gas worldwide. Geothermal resources are found in a wide range of depths, from shallow surface to several kilometers deep reservoir of hot water and steam that can be brought to the surface and utilized. Its advantage, in addition to the enormous potential, is that it has negligible negative impact on the environment. The main disadvantages are the dependence of its exploitation from the position, depth, temperature and amount of water in a given geothermal reservoir.

Although the geothermal energy has been used for heating purposes for centuries, until the twentieth century people have not found a way how to use this hot steam energy to drive a turbine and produce electricity.

A typical geothermal power plants units include a borehole for drawing hot steam, a tank for acceptance steam, a steam cleaners, a steam turbine and a generator, as well as appropriate condenser in which the steam transform in liquid phase. Therefore, the fire risks of these plants similar to conventional power plants, but significantly lower because the process of steam and electricity production are taking place without any combustion process.

Water steam must have a sufficiently high temperature and pressure that could be used for producing electricity. Although it is supposed that the deep wells (depth of over $2 \mathrm{~km}$ ), could have such water steam parameters, such sources has not been yet found in Serbia.

\subsection{Hydropower}

Hydropower or water power is power derived from the energy of falling water and running water, which may be harnessed for useful purposes. Since ancient times, hydropower has been used for irrigation and the operation of various mechanical devices, such as watermills, sawmills, textile mills, dock cranes, domestic lifts, power houses and paint making. Since the early twentieth century, the term is used almost exclusively in conjunction with the modern development of hydro-electric power, which allowed use of distant energy sources.

While all hydro power plants generate renewable energy, the term renewable is usually used only for so-called small power plants.

Because of to its prevalence in many countries, this type of renewable energy is taking a significant share in the total production and consumption of energy. In Serbia, $30 \%$ of the total electricity produced in this way, which makes up about $10 \%$ of the total energy consumed in Serbia.

Except inaccessibility, which cannot be avoided because of the logic of using this potential, due to the absence of the combustion process, fire risks for small hydroelectric power facilities, in comparison to other power plants for electricity generation are identical or lower.

\section{Conclusions}

The overall development of society and the need for sustainable energy systems, unstoppably lead to extensive application of technologies for exploitation of renewable energy. Some of them are already widely used, such as solar collectors, wind turbines, hydropower plants, while some, such as fuel cells and use of hydrogen, are still at threshold of future mass production. In order to provide that use of renewable energy sources make tomorrow's world better, 
healthier and safer to live, the development and use of appropriate technology and applied materials is necessary to accompany with considerations of the fire risk. From this point of view, additional reviewing and identifying high-risks in the development of practical solutions and practical guidance has essential importance for different types of further application of this technologies and their diversification.

\section{Acknowledgment}

This paper is made in a scope of the project TR 33047 "Intelligent climate control systems to achieve energy efficient regime in the complex conditions of exploitation" funded by the Ministry of Education, Science and Technological Development of the Republic of Serbia.

\section{References}

[1] Renewables Information 2013, International Energy Agency, Paris, 2013.

[2] Directive 2009/28/EC of the European Parliament and of the Council of 23 Apr. 2009 on the Promotion of the use of Energy from Renewable Sources and Amending and Subsequently Repealing Directives 2001/77/EC and 2003/30/EC, European Parliament, 2009.

[3] Law on Energy, Official Gazette of the Republic of Serbia, the Republic of Serbia, No. 57/2011, 2011.

[4] Regulation on Conditions for Acquiring the Status of Privileged Producer of Electricity and the Criteria for
Assessment of Compliance with These Requirements, Official Gazette of the Republic of Serbia, No. 72/2009, European Parliament, 2009.

[5] Smart Green Solutions Solar PV Burning Issue Home Page,

http://smart-greensolutions.blogspot.com/2012/09/solar-p v-burning-issue-until-solace-was.html (accessed Nov. 10, 2013).

[6] Spiegel Online, European Platform Against Wind Farms Proof Wind Turbines Take Thousands off Your Home Home Page, http://www.epaw.org/multimedia.php?article=a7 (accessed Nov. 10, 2013).

[7] Flickr, Photos That Capture Destruction Caused by Nature and/or Human Behaviour Home Page, http://www.flickr.com/photos/digifotovet/7796686568/ (accessed November 10, 2013).

[8] L. Dupont, A. Accorsi, Explosion Characteristics of Synthesised Biogas at Various Temperatures, Journal of Hazardous Materials 136 (2006) 520-525.

[9] Principles of Explosion Protection-System Manual, Siemens AG, Nurnberg, Germany, 2010.

[10] Directive 99/92/EC of the European Parliament and of the Council of 16 Dec. 1999 on Minimum Requirements for Improving the Safety and Health Protection of Workers Potentially at Risk from Explosive Atmospheres (15th Individual Directive within the Meaning of Article 16 (1) of Directive 89/391/EEC), European Parliament, 1999.

[11] Directive 94/9/EC of the European Parliament and of the Council of 23 Mar. 1994 on the Approximation of the Laws of Members States Concerning Equipment and Protective Systems Intended for Use in Potentially Explosive Atmospheres, European Parliament, 1994. 